Tohoku J. exp. Med., 1983, 140, 109-119

\title{
The Effect of Adrenergic and Cholinergic Drugs on Methacholine- and Histamine-Induced Bronchoconstriction in Monkeys
}

\author{
Suetsugu Mue, Tetsuhiro Ohmi, Shunsuke Suzuki, Gen \\ Tamura, Wataru Hida, Kiyohisa Sekizawa, Toshiharu \\ Ishihara, Kohei Yamauchi and Tamotsu Takishima \\ First Department of Internal Medicine, Tohoku University \\ School of Medicine, Sendai 980
}

\begin{abstract}
Mue, S., Ohmi, T., Suzuki, S., Tamura, G., Hida, W., Sekizawa, K., Ishinara, T., Yamauchi, K. and Takishima, T. The Effect of Adrenergic and Cholinergic Drugs on Methacholine- and Histamine-Induced Bronchoconstriction in Monkeys. Tohoku J. exp. Med., 1983, 140 (2), 109-119 — The effect of adrenergic and cholinergic drugs on bronchial contraction of monkeys was studied using bronchoconstriction induced by aerosol challenge with methacholine and histamine. Under the anesthesia with ketamine hydrochloride, changes in the total respiratory resistance were continuously measured in monkeys to estimate the bronchial response to both histamine and methacholine. Isoprenaline decreased bronchial susceptibility to aerosol challenge with both methacholine and histamine. Isoprenaline was also potent in antagonizing the bronchoconstriction induced by methacholine and histamine. Atropine decreased bronchial susceptibility to aerosol challenge with methacholine and also partially with histamine. Atropine also antagonized the bronchoconstriction induced by methacholine, but not by histamine. Phentolamine had neither inhibitory effects on the aerosol challenge with methacholine and histamine, nor produced an antagonistic effect on bronchoconstriction induced with methacholine and histamine. - bronchial response; methacholine and histamine; adrenergic and cholinergic drugs; monkeys
\end{abstract}

Human IgE has been locally and systemically transferred to monkeys (Straus 1937). In the passive sensitization of monkeys, the aerosol delivery of antigen could induce an acute respiratory response (Patterson and Kelley 1974). Because antihuman $\operatorname{IgE}$ crossly reacted with $\operatorname{IgE}$ of rhesus monkeys, the aerosol delivery of anti-IgE could produce the immediate type respiratory response (Patterson et al. 1971). In some monkeys sensitive to the ascaris antigens, the aerosolized antigen produced an acute allergic bronchoconstriction. There has been shown a similarity between the human asthmatic attack and the changes in pulmonary function of these monkeys when exposed to the antigen (Patterson and Kelly 1974). Thus, monkeys is thought as an appropriate model of acute allergic bronchoconstriction (Patterson and Harris 1976).

There are three known mechanisms by which the adrenergic and cholinergic drugs can produce bronchoconstriction in human beings: (1) cholinergic stimulate,

Received for publication, September 28, 1982. 
(2) beta-adrenergic block, and (3) alpha-adrenergic stimulate, corresponding to "cholinergic hyperreactivity" (Nadel 1976), "beta-adrenergic blockade" (Szentivanyi 1968 ) and "alpha-adrenergic hyperreactivity" (Simonsson et al. 1972), respectively.

In our laboratory, the possibility that monkeys could provide a useful basis for studying the autonomic nervous system in relation to the pathogenesis of human bronchial asthma has been investigated (Mue et al. 1980). Using the forced $3 \mathrm{~Hz}$ oscillation method, changes in respiratory impedance have been successfully measured in monkeys to estimate the bronchial response to histamine or methacholine. In our previous report (Mue et al. 1980), treatment with propranolol was shown to increase the bronchial response of monkeys to intravenously injected methacholine, but neither to aerosolized methacholine, nor to histamine irrespective of the route of administration. Now we are able to estimate respiratory resistance (Rrs) by calculating the respiratory impedance with an analogue-circuit. Using induced bronchoconstriction of monkeys, we extended our experiments to study the homeostasis of the airways and the mechanism of bronchial constriction and relaxation in monkeys in relation to the autonomic nervous system.

Firstly, we studied the antagonistic effect of isoprenaline, as a beta-adrenergic stimulating agent, on bronchial constriction induced by histamine or methacholine. We also studied the effects of atropine as an anticholinergic agent and phentolamine as an alpha-adrenergic blocking agent on this experimentally induced bronchoconstriction in monkeys.

\section{Material and Methods}

\section{Monkeys}

Eleven Japanese monkeys (Macaca fuscata) were selected from a colony that was wellfed and free of disease including any infections. Monkeys consisted of 8 males and 3 females. Their body weight ranged from 6.2 to $13.7 \mathrm{~kg}$ ( $8.9 \mathrm{~kg}$ as mean) and ages from 3.2 to 7.5 years (5.7 years as mean). The animals were isolated from one another and given a diet of solid feed (Oriental Kobo, Tokyo), fruit and water with vitamins during the study.

\section{Anesthesia}

Anesthesia was induced by an intramuscular injection (i.m.) of ketamine hydrochloride $(5 \mathrm{mg}$ per $\mathrm{kg}$ ) and maintained by additional injections of ketamine, approximately $1.5 \mathrm{mg}$ per $\mathrm{kg}$ per $20 \mathrm{~min}$. As previously reported (Mue et al. 1980), the dosage was adjusted to maintain a steady state of anesthesia as indicated by a normal spontaneous respiration pattern, the presence of light and corneal reflexes and the absence of grasp reflexes. This dose of ketamine did not change the base-line Rrs and heart rate (HR). Under ketamine anesthesia, the pharyngeal and laryngeal reflexes remained intact and the upper respiratory airway remained patent. The presence of cough reflex was checked by physical stimulation of the upper part of the tracheo-bronchial tract using a vinyl catheter inserted through the endotracheal tube. During the intravenous injection of adrenergic and cholinergic drugs as well as the aerosol challenge, no additional dose of ketamine was injected to the monkeys.

\section{Aerosol challenge with methacholine or histamine}

Aerosol challenge with methacholine or histamine was carried out as previously reported (Mue et al. 1980). Briefly, the concentration of the methacholine solution for aerosol 
challenge ranged from 0.01 to $1 \%(\mathrm{w} / \mathrm{v})$. The concentration of histamine solution for the aerosol challenge ranged from 0.01 to 1 percent $(\mathrm{w} / \mathrm{v})$. All solutions of methacholine and histamine were freshly prepared before administration. Methacholine and histamine were aerosolized by an ultrasonic nebulizer (Nihon Koden, Tokyo). The monkeys were exposed to these aerosolized drugs through an endotracheal tube for 40 spontaneous breaths (about $60 \mathrm{sec}$ ). While this aerosol challenge, the respiratory pattern of monkeys did not change. Then, Rrs gradually began to increase with rapid and deep breathing.

\section{The administration of isoprenaline, atropine and phentolamine}

Isoprenaline hydrochloride (Nikken Kagaku, Tokyo), atropine sulfate (Dai-ichi Kagaku, Tokyo) and phentolamine (Ciba-Takeda, Tokyo) were dissolved in $5 \%$ glucose and water and intravenously injected (i.v.) at a steady rate. The dosage of the administered isoprenaline ranged from 1 to $100 \mu \mathrm{g} / \mathrm{kg}$ of body weight, atropine from 0.01 to $2 \mathrm{mg}$ and phentolamine from 0.1 to $20 \mathrm{mg}$. The concentration of injected isoprenaline was 1 and $50 \mu \mathrm{g}$ per $\mathrm{ml}$ of $5 \%$ glucose and water, atropine $10 \mu \mathrm{g}$ and $1 \mathrm{mg}$ and phentolamine 0.1 to $10 \mathrm{mg}$, respectively.

The antagonistic effects of these drugs on bronchoconstriction were studied before and after aerosol challenge with methacholine or histamine. To study the protective effects of these drugs, two doses of isoprenaline and atropine were selected; one was low to produce a slight reduction of base-line Rrs and the other was high to produce more reduction of Rrs, but a marked increase in HR. On the other hand, more than $10 \mathrm{mg}$ of phentolamine were not used due to excessive lowering of systemic blood pressure. After estimating base-line Rrs, these drugs were intravenously injected and the aerosol challenge was continuously carried out within $15 \mathrm{~min}$ as documented in the section dealing with our results.

To study myorelaxant effects, monkeys were exposed to these bronchoconstrictors. Then, these three drugs were continuously injected at a steady rate for $8 \mathrm{~min}$ just after challenging as shown in Fig. 4, because the elevated Rrs after the aerosol challenge with methacholine or histamine began to decrease at $10 \mathrm{~min}$.

In every experiment, monkeys were treated with each of these drugs at least 2 times at satisfactory intervals (more than 4 weeks). Six to 11 monkeys were used in each experimental group. The data were presented as mean and standard deviation of all trials.

\section{Measurement of total respiratory resistance}

As previously reported (Mue et al. 1980), all monkeys were measured in an upright position and breathed on the oscillator through the inserted endotracheal tube. Total respiratory impedance was measured by the forced $3 \mathrm{~Hz}$ oscillation technique (Grimby et al. 1968) mentioned in the previous report (Mue et al. 1980). To explain briefly, oscillating air flows were produced by bellows that were driven by a motor-operated system at a fixed frequency. The airway pressure was measured near the proximal portion of the endotracheal tube with a pressure transducer (Hewlett-Packard 270, California). Airflow was measured between the endotracheal tube and the oscillating generator with a hot-wire flow transducer (Minato RF-L, Tokyo). Bias flow was continuously drawn at about 0.3 liter/ sec between the endotracheal tube and the oscillating generator to prevent $\mathrm{CO}_{2}$ build-up in the system. The airway pressure, airflow and integrated airflow (tidal volume), and ECG were recorded by a magnetic tape-recorder (Sony RMG-5104, Tokyo) and simultaneously monitored on a four-channel direct-writing recorder (Sanei oscillograph 8L-12, Tokyo). The taped data were played back and the collected total respiratory impedance was calculated into the total Rrs by an analogue circuit according to Hyatt and his coworkers' formula (Hyatt et al. 1970).

\section{Analysis}

Student's $t$-test was used for the statistical evaluation of differences of average values. 


\section{Results}

Figs. 1, 2 and 3 show the percent change of Rrs and HR from base-line after the intravenous injection of the cumulative doses of isoprenaline, atropine and phentolamine, respectively. Isoprenaline, ranging from 1 to $10 \mu \mathrm{g} / \mathrm{kg}$, decreased Rrs and a dose of $10 \mu \mathrm{g}$ decreased Rrs by $35 \%$ and increased HR by $10 \%$ (Fig. 1). Atropine, ranging from 10 to $100 \mu \mathrm{g} / \mathrm{kg}$, decreased Rrs in a dose related fashion, but doses exceeding $100 \mu \mathrm{g} / \mathrm{kg}$ did not decrease Rrs further and cause a marked increase in HR (Fig. 2). Phentolamine (1 to $10 \mathrm{mg} / \mathrm{kg}$ ) increased dose-dependently $\mathrm{HR}$ in all monkeys without changing Rrs and $20 \mathrm{mg} / \mathrm{kg}$ phentolamine decreased Rrs by $25 \%$ with a marked increase in HR (Fig. 3).

Table 1 shows the changes in Rrs due to the aerosol challenge with methacholine after injection of isoprenaline, atropine or phentolamine. Pretreatment with $5 \mu \mathrm{g} / \mathrm{kg}$ of isoprenaline suppressed an increase in Rrs produced by aerosol challenge with methacholine ranging from 0.01 to $0.1 \%$. The previous injection of $50 \mu \mathrm{g} / \mathrm{kg}$ of isoprenaline also significantly suppressed the increase in Rrs caused by aerosol challenge with methacholine. Pretreatment with $50 \mu \mathrm{g} / \mathrm{kg}$ of atropine significantly suppressed the increase in Rrs due to aerosol challenge with 0.01 to $1 \%$ of methacholine. The injection of $500 \mu \mathrm{g} / \mathrm{kg}$ of atropine kept Rrs below the baseline in spite of aerosol challenge with methacholine in concentrations up to $0.5 \%$ and markedly suppressed an increase of Rrs with even $1 \%$ methacholine.

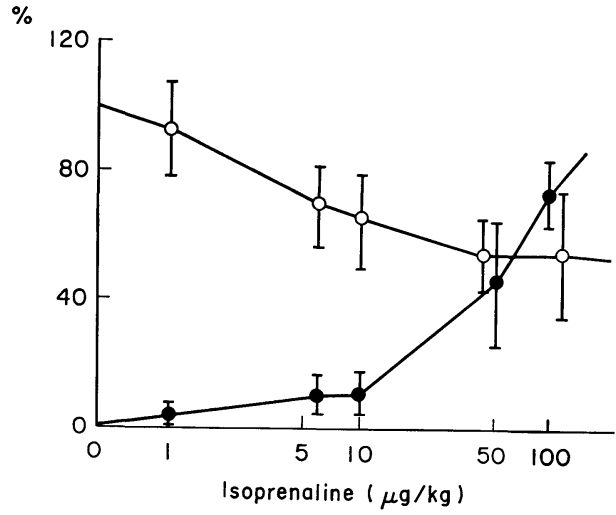

Fig. 1

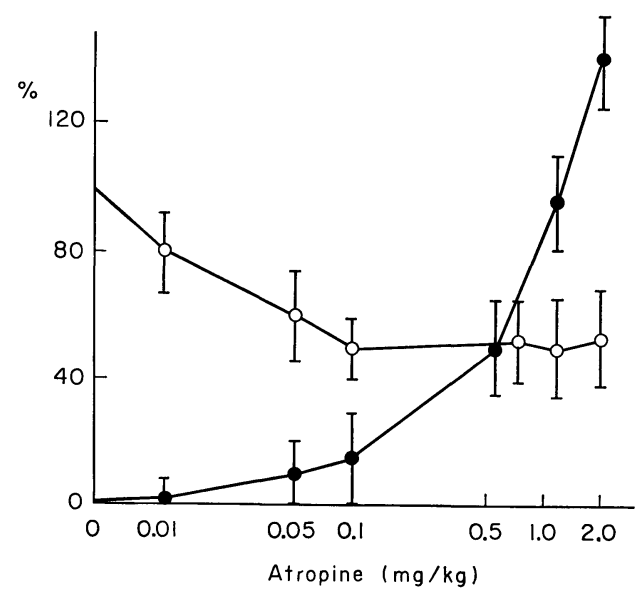

Fig. 2

Fig. 1. Dose-response curves for the effect of isoprenaline on Rrs and HR in monkeys. The changes of Rrs (open circles) and HR (closed circles) are shown in terms of percent decrease and percent increase of the value before injection, respectively. Data are presented as the mean (point) and standard deviation (bar) of 14 experiments (conducted in 7 monkeys).

Fig. 2. Dose response curve for the effect of atropine on Rrs and HR in monkeys. Data are presented as the mean and standard deviation of 16 experiments (conducted in 8 monkeys).

The other conditions are the same as described in Fig. 1. 
Fig. 3. Dose response curve for the effect of phentolamine on Rrs and HR in monkeys. Data are presented as the mean and standard deviation of 20 experiments (conducted in 10 monkeys).

The other conditions are the same as described in Fig. 1.

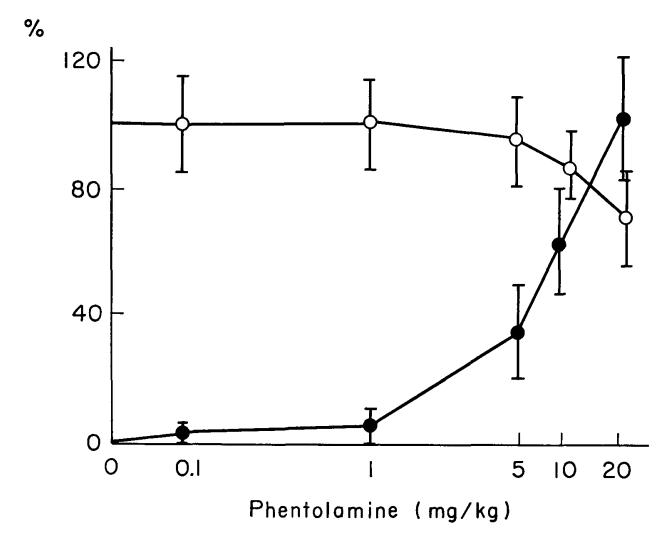

TABLE 1. The effect of pretreatment with isoprenaline, atropine or phentolamine on aerosol challenge with methacholine

\begin{tabular}{|c|c|c|c|c|c|c|c|}
\hline \multirow{4}{*}{$\begin{array}{l}\text { Concentration } \\
\text { of challenged } \\
\text { methacholine } \\
\% \\
\%\end{array}$} & \multirow{4}{*}{$\begin{array}{c}\text { Untreatment } \\
\text { (16) }\end{array}$} & \multicolumn{3}{|c|}{ Rrs after aerosol challenge } & \multicolumn{2}{|c|}{$\mathrm{cmH}_{2} \mathrm{O} / 1 / \mathrm{sec}$} & \\
\hline & & \multicolumn{6}{|c|}{ Pretreatment with } \\
\hline & & \multicolumn{2}{|c|}{ Isoprenaline } & \multicolumn{2}{|c|}{ Atropine } & \multicolumn{2}{|c|}{ Phentolamine } \\
\hline & & $\begin{array}{l}5 \\
(8)\end{array}$ & $\begin{array}{c}50 \\
(16) \\
\mu \mathrm{g} / \mathrm{kg}\end{array}$ & $\begin{array}{c}50 \\
(14)\end{array}$ & $\begin{array}{c}500 \\
(16) \\
\mu \mathrm{g} / \mathrm{kg}\end{array}$ & $\begin{array}{l}5 \\
(16)\end{array}$ & $\begin{array}{c}10 \\
(16) \\
\mathrm{mg} / \mathrm{kg}\end{array}$ \\
\hline Before & $3.9 \pm 0.9$ & $2.4 \pm 0.4^{*}$ & $2.1 \pm 0.6^{*}$ & $2.2 \pm 0.3^{*}$ & $2.3 \pm 0.4^{*}$ & & $3.2 \pm 0.7$ \\
\hline 0.01 & $4.5 \pm 1.1$ & $2.7 \pm 0.7^{*}$ & $2.1 \pm 0.5 \dagger$ & $2.9 \pm 0.9 *$ & $2.2 \pm 0.5 \dagger$ & $4.2 \pm 0.9$ & $4.2 \pm 1.2$ \\
\hline 0.05 & $5.7 \pm 1.4$ & $3.1 \pm 1.5 \dagger$ & $2.4 \pm 0.9 \dagger$ & $3.1 \pm 0.9 *$ & $2.4 \pm 0.5 \dagger$ & $5.7 \pm 1.2$ & $4.2 \pm 1.5$ \\
\hline 0.1 & $7.0 \pm 2.1$ & $3.2 \pm 1.2 \dagger$ & $2.4 \pm 1.1 \dagger$ & $4.2 \pm 1.5^{*}$ & $3.0 \pm 1.1 \dagger$ & $7.6 \pm 1.9$ & $7.5 \pm 1.9$ \\
\hline 0.5 & $8.2 \pm 2.5$ & $3.9 \pm 1.4 \dagger$ & $2.9 \pm 1.2 \dagger$ & $4.4 \pm 1.9 \dagger$ & $3.9 \pm 1.3 \dagger$ & $8.5 \pm 2.3$ & $8.2 \pm 1.8$ \\
\hline 1.0 & $8.6 \pm 1.9$ & $4.1 \pm 1.5 \dagger$ & $3.4 \pm 1.4 \dagger$ & $5.6 \pm 2.1 \dagger$ & $5.0 \pm 1.5 \dagger$ & $9.1 \pm 2.3$ & $9.1 \pm 2.1$ \\
\hline
\end{tabular}

The values are the mean and standard deviation. Each figure in the parenthesis represents the number of experiments conducted in 8 monkeys.

$* p<0.01 ; \dagger p<0.001$ for the difference from untreated control (horizontal comparison).

Pretreatment with 5 and $10 \mathrm{mg} / \mathrm{kg}$ of phentolamine did not suppress an increase in Rrs induced by the aerosol challenge with methacholine.

Table 2 shows the changes in Rrs due to the aerosol challenge with histamine after the injection of isoprenaline, atropine or phentolamine. Pretreatment with $5 \mu \mathrm{g} / \mathrm{kg}$ of isoprenaline slightly suppressed the increase in Rrs due to aerosol challenge with histamine in concentrations up to $0.5 \%$. The injection of $50 \mu \mathrm{g} / \mathrm{kg}$ of isoprenaline significantly suppressed an increase in $\operatorname{Rrs}$ due to aerosol challenge with 0.01 to $1 \%$ histamine. Pretreatment with $50 \mu \mathrm{g} / \mathrm{kg}$ of atropine suppressed an increase in Rrs due to the aerosol challenge with up to $0.1 \%$ histamine but not with more than $0.5 \%$ histamine. The injection of $500 \mu \mathrm{g} / \mathrm{kg}$ of atropine significantly suppressed an increase in Rrs due to aerosol challenge with up to $0.5 \%$ histamine, but not with $1 \%$. The injection of both 5 and $10 \mathrm{mg} / \mathrm{kg}$ of phentolamine did not suppress the increase in Rrs due to aerosol challenge with 0.01 to $1 \%$ histamine. 
TABLE 2. The effect of pretreatment with isoprenaline, atropine or phentolamine on aerosol challengte with histamine

\begin{tabular}{|c|c|c|c|c|c|c|c|}
\hline \multirow{4}{*}{$\begin{array}{c}\text { Concentration } \\
\text { of challenged } \\
\text { histamine } \\
\%\end{array}$} & \multirow{4}{*}{$\begin{array}{c}\text { Untreatment } \\
(8)\end{array}$} & \multicolumn{3}{|c|}{ Rrs after aerosol challenge } & \multicolumn{3}{|c|}{$\mathrm{cm} \mathrm{H}_{2} \mathrm{O} / 1 / \mathrm{sec}$} \\
\hline & & \multicolumn{6}{|c|}{ Pretreatment with } \\
\hline & & \multicolumn{2}{|c|}{ Isoprenaline } & \multicolumn{2}{|c|}{ Atropine } & \multicolumn{2}{|c|}{ Phentolamine } \\
\hline & & $\begin{array}{l}5 \\
(8)\end{array}$ & $\begin{array}{c}50 \\
(16) \\
\mu \mathrm{g} / \mathrm{kg}\end{array}$ & $\begin{array}{c}50 \\
(14)\end{array}$ & $\begin{array}{c}500 \\
(16) \\
\mu \mathrm{g} / \mathrm{kg}\end{array}$ & $\begin{array}{c}5 \\
(16)\end{array}$ & $\begin{array}{c}10 \\
(16) \\
\mathrm{mg} / \mathrm{kg}\end{array}$ \\
\hline Before & $3.8 \pm 0.8$ & $2.0 \pm 0.5^{*}$ & $1.8 \pm 0.4^{*}$ & $2.2 \pm 0.2^{*}$ & $1.9 \pm 0.2^{*}$ & $3.7 \pm 0.8$ & $3.2 \pm 0.5$ \\
\hline 0.01 & $4.2 \pm 1.2$ & $2.1 \pm 0.6^{*}$ & $1.9 \pm 0.5 \dagger$ & $2.4 \pm 0.4^{*}$ & $2.2 \pm 0.3^{*}$ & $4.2 \pm 0.9$ & $4.2 \pm 0.9$ \\
\hline 0.05 & $5.4 \pm 1.3$ & $2.4 \pm 0.6 \dagger$ & $2.1 \pm 0.5 \dagger$ & $2.9 \pm 0.5^{*}$ & $3.0 \pm 0.5^{*}$ & $5.5 \pm 1.1$ & $5.2 \pm 1.6$ \\
\hline 0.1 & $6.9 \pm 1.9$ & $2.6 \pm 0.8 \dagger$ & $2.3 \pm 0.6 \dagger$ & $5.9 \pm 1.1$ & $3.1 \pm 0.9^{*}$ & $6.9 \pm 1.5$ & $7.3 \pm 1.9$ \\
\hline 0.5 & $7.7 \pm 2.3$ & $3.4 \pm 1.1 \dagger$ & $2.5 \pm 0.9 \dagger$ & $7.1 \pm 2.2$ & $5.1 \pm 1.9^{*}$ & $7.9 \pm 1.4$ & $8.4 \pm 1.7$ \\
\hline 1.0 & $8.6 \pm 2.0$ & $4.5 \pm 1.5 \dagger$ & $3.1 \pm 0.7 \dagger$ & $8.3 \pm 2.7$ & $7.4 \pm 2.1$ & $8.8 \pm 1.9$ & $9.4 \pm 2.1$ \\
\hline
\end{tabular}

The values are the mean and standard deviation. Same monkeys were used as in

Table 1. The symbols are the same as Table 1 .

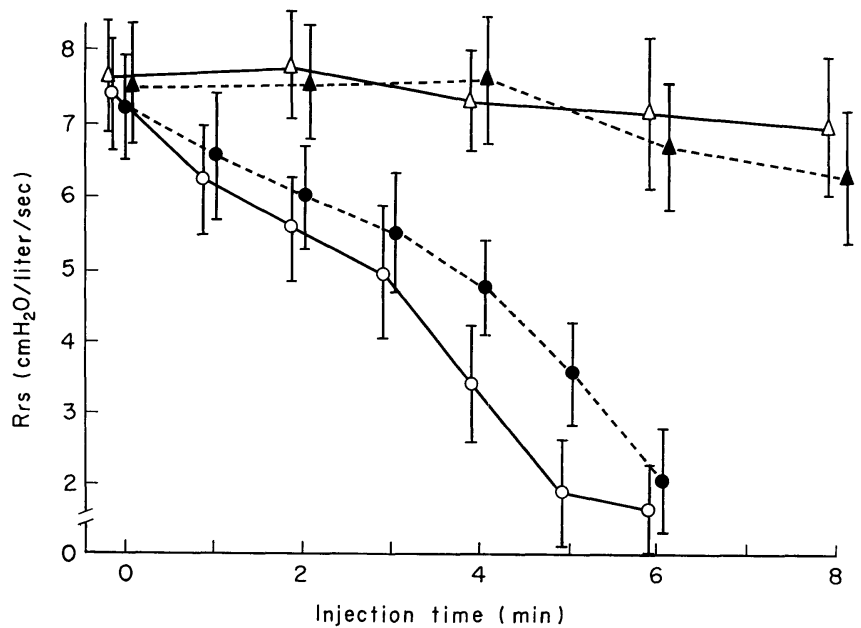

Fig. 4. The effect of isoprenaline, atropine or phentolamine on bronchoconstriction induced by methacholine.

Each point and bar indicate the mean and standard deviation of the following numbers of experiments.

○-०: Isoprenaline (12 experiments) was intravenously injected at the rate of $10 \mu \mathrm{g}$ per $\mathrm{kg}$ of body weight per min.

---- Atropine (14 experiments) was injected at the rate of $50 \mu \mathrm{g}$ per $\mathrm{kg}$ per min. $\Delta-\Delta$ : Phentolamine (18 experiments) was injected at the rate of $1 \mathrm{mg}$ per $\mathrm{kg}$ per $\min$.

$\Delta--\Delta$ : No treatment (12 experiments).

$* p<0.01 . \dagger p<0.001$.

" $p$ " values are vs. untreated control (vertical comparisons).

In Fig. 4, the effects of isoprenaline, atropine and phentolamine on bronchoconstriction induced by aerosol challenge with $1 \%$ methacholine are shown. The intravenous injection of isoprenaline markedly decreased $\operatorname{Rrs}$ and $10 \mu \mathrm{g} / \mathrm{kg} /$ 
min of isoprenaline for 5 min decreased Rrs below the base-line. The injection of atropine dose-dependently decreased Rrs and $50 \mu \mathrm{g} / \mathrm{kg} / \mathrm{min}$ of atropine for $6 \mathrm{~min}$ produced a decrease to the base-line. The injection of $1 \mathrm{mg} / \mathrm{kg} / \mathrm{min}$ of phentolamine for $8 \mathrm{~min}$ did not significantly decrease Rrs. Fig. 5 shows the effects of

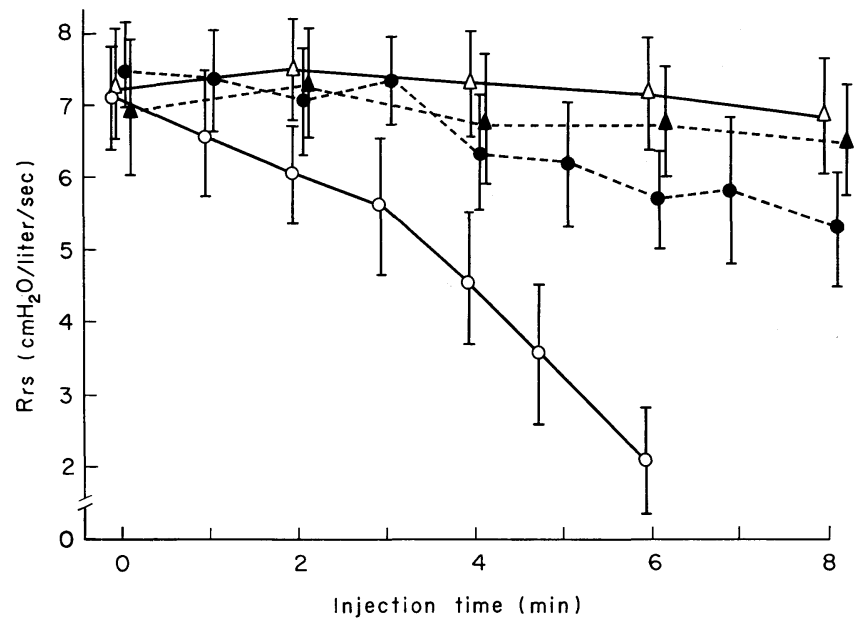

Fig. 5. The effect of isoprenaline, atropine or phentolamine on bronchoconstriction induced by histamine.

Besides the numbers of experiments for each drug, this study was carried out under the same conditions as described in Fig. 4.

The numbers of experimənts were as follows: 12 for isoprenaline, 14 for atropine, 16 for phentolamine and 12 for no treatment. The symbols and the dosages are the same as Fig. 4.

isoprenaline, atropine and phentolamine on bronchoconstriction induced by aerosol challenge with $1 \%$ histamine. Continuous infusion of isoprenaline $(10 \mu \mathrm{g} / \mathrm{kg} / \mathrm{min})$ for 4 to $6 \mathrm{~min}$ also time-dependently decreased Rrs below the base-line, but continuous infusion $(50 \mu \mathrm{g} / \mathrm{kg} / \mathrm{min})$ of atropine up to $8 \mathrm{~min}$ slightly decreased Rrs. Doses ranging up to $8 \mathrm{mg}$ of phentolamine ( $1 \mathrm{mg} / \mathrm{kg} / \mathrm{min}$, up to $8 \mathrm{~min}$ ) did not act as a myorelaxant for bronchoconstriction induced by aerosol challenge with $1 \%$ histamine.

\section{Discussion}

As previously reported (Mue et al. 1980), we have established a continuous and stable method for detecting the respiratory responses of monkeys by using the forced $3 \mathrm{~Hz}$ oscillation technique. Methacholine and histamine dose-dependently increased the total respiratory impedance in monkeys by aerosol challenge as well as intravenous injection. We have confirmed that the observed changes of impedance in monkeys are similar to the increase of impedance of provoked attacks in asthmatic patients. In this experiment, we studied the participation of the adrenergic receptor and cholinergic receptor on bronchoconstriction of monkeys induced by aerosol challenge with methacholine or histamine. 
Isoprenaline is known to have a powerful action on all beta-receptors and almost no action on alpha-receptors. The intravenous injection of isoprenaline lowers peripheral vascular resistance and raises cardiac output by an increase in the venous return to the heart in combination with positive inotropic and chronotropic actions (Weiner 1980b). In this study, doses ranging from 1 to $10 \mu \mathrm{g} / \mathrm{kg}$ of isoprenaline dose-dependently decreased Rrs from base-line and increased HR to a relatively slight degree in monkeys. More than $50 \mu \mathrm{g} / \mathrm{kg}$ of isoprenaline did not produce a further decrease in Rrs, but evoked a marked increase in HR. Pretreatment with isoprenaline significantly suppressed the bronchial response to methacholine and histamine. The injection of doses ranging up to $60 \mu \mathrm{g} / \mathrm{kg}$ of isoprenaline dose-dependently showed a myorelaxant effect on bronchoconstriction induced with methacholine and histamine. Thus, isoprenaline was shown to have a direct myorelaxant action on the effects of methacholine and histamine, and a myostabilizing effect, probably derived from its beta-stimulating activity.

In dogs sensitive to ascaris antigen, ketamine (10 $\mathrm{mg}$ per $\mathrm{kg}$ i.v. for induction and $3 \mathrm{mg}$ per $\mathrm{kg}$ per $15 \mathrm{~min}$ i.v. for maintenance) blocked an increase of pulmonary airway resistance after exposing to antigen, probably through its beta-adrenergic stimulating effect (Hirshman et al. 1979). In monkeys anesthetized with ketamine $(5 \mathrm{mg}$ per $\mathrm{kg}$ i.m. for induction and $1.5 \mathrm{mg}$ per $\mathrm{kg}$ per $20 \mathrm{~min}$ i.m. for maintenance), methacholine and histamine dose-dependently increased the total respiratory resistance by aerosol challenge in this study as well as intravenous injection in the previous report.

Histochemical analysis of the human airway reveals a dense network of parasympathetic fibers that appear to control normal airway tone (Cabezas et al. 1971). Asthmatic patients are excessively sensitive to inhaled or injected cholinergic agonists, leading to bronchoconstriction. Stimulation of the cholinergic system produced the acceleration of in vitro immunologic release of mediator (Kaliner et al. 1972), and the direct induction of smooth muscle contraction ( $\mathrm{Yu}$ et al. 1972).

In monkeys, methacholine (Mue et al. 1980) and carbacholine (Miller et al. 1976) induced bronchoconstriction. Less than $100 \mu \mathrm{g} / \mathrm{kg}$ of atropine dosedependently decreased base-line Rrs and increased HR in the monkeys. This systemically administered atropine is thought to produce an antimuscarinic action also on bronchial smooth muscle (Weiner 1980a). This evidence suggests that the bronchial tone of monkeys is considerably controlled by the cholinergic nervous system. More than $100 \mu \mathrm{g} / \mathrm{kg}$ of atropine did not produce a further decrease in baseline Rrs but caused a marked increase in HR. The observed increase in HR is thought to be probably due to sufficient doses of atropine blocking the vagal effect on the sinus-atrium pacemaker. This also suggests that vagal tone of monkeys is high, because the influence of atropine on heart rate is most noticeable in healthy young adult human beings, in whom vagal tone is at its height (Weiner 1980a).

The dose of atropine studied significantly suppressed the bronchial response to 
methacholine, and partially suppressed that to histamine. Atropine is known to be particularly effective against bronchoconstriction produced by parasympathomimetic drugs such as methacholine and anticholinesterase agents (Weiner 1980a). In monkeys, atropine antagonized the effects of aerosolized methacholine by blocking the efferent nerve limb of the vagally induced reflex brochonconstriction arc. Methacholine is thought to cause bronchial obstruction through cholinergic pathway (Spector and Farr 1975), while histamine is thought to trigger bronchoconstriction through an irritant receptor parasympathetic reflex mechanism (Simonsson et al. 1967) as well as by a direct effect on bronchial smooth muscle. Atropine was shown to inhibit the action of histamine given at low doses but not in high doses (Drazen et al and Austen 1975). Thus, pretreatment with atropine changed the bronchial susceptibility of monkeys to histamine to a relative degree, probably by blocking the vagal reflex of the efferent nerve. The injection of atropine dose-dependently showed a myorelaxant effect on bronchoconstriction induced by aerosol challenge with methacholine, but failed to decrease the elevated Rrs induced with histamine. In monkey, isoprenaline had a myorelaxant effect on bronchoconstriction previously induced by aerosol challenge with histamine, but atropine did not.

The existence of alpha-adrenergic receptors has been shown not only in the trachea of experimental animals (Fleish et al. 1970), but also in the isolated human bronchi (Mathé et al. 1971). Several lines of evidence suggest that abnormal alpha-adrenergic function may also contribute to asthma; alphaadrenergic agonists enhance mediator release from human lung cells (Kaliner et al. 1972), alpha-adrenergic stimulation of both animal and human bronchial muscle in vitro produces constriction (Mathé et al. 1971; Simonsson et al. 1972) and alphaadrenergic blocking agents may prevent the bronchospasm induced by histamine and exercise (Kerr et al. 1970). Recently, enhanced alpha-adrenergic responses of asthmatic patients were shown not only in the respiratory tract, but also in other organs such as the cutaneous vascular bed or the pupillary sphincter muscle (Henderson et al. 1979). The effect of several alpha-adrenergic blocking agents on human bronchial asthma has been investigated and some of them, including phentolamine, have been shown to have a bronchodilating effect (Gross et al. 1974; Biel and de Kock 1978).

We studied the effect of phentolamine on Rrs and HR in monkeys before and after aerosol challenge with methacholine or histamine. Doses ranging up to 20 $\mathrm{mg} / \mathrm{kg}$ of phentolamine produced marked cardiac stimulation, but a slight decrease in base-line Rrs. These doses of phentolamine also produced incontinence of urine and feces in many monkeys, probably through hyperperistalsis of the gastrointestinal and urinary tracts (Weiner 1980c). Thus, these doses of phentolamine produced a "sympathomimetic effect" on the heart and not on the airways, and a "parasympathomimetic effect" on the bowel in monkeys. The monkeys' recovery from ketamine anesthesia was prolonged by the injection of more than $20 \mathrm{mg} / \mathrm{kg}$ of phentolamine. The monkeys were observed to be inactive 
for a few days after the injection of over $20 \mathrm{mg} / \mathrm{kg}$ of phentolamine. Although we could not measure the blood pressure of all the monkeys throughout these experiments, this dose of phentolamine decreased systolic blood pressure by more than $35 \%$ in some monkeys. According to the results of this study, phentolamine could not protect monkeys from aerosol challenge with methacholine or histamine, nor produced myorelaxant action on the bronchoconstriction previously induced by aerosol challenge with methacholine.

In conclusion, isoprenaline is the most potent in inhibiting the bronchial response to both histamine and methacholine and also has direct myorelaxing effects on bronchoconstriction caused by both agents in monkeys. This evidence suggests that isoprenaline could overcome the bronchoconstriction induced by cholinergic stimulation. Atropine is shown to produce inhibitory and myorelaxant effects on bronchoconstriction induced with methacholine through its antimuscarinic action. In monkeys, histamine is possibly shown to trigger bronchoconstriction through an irritant receptor mechanism as well as by a direct effect on bronchial smooth muscle.

\section{Acknowledgments}

We wish to thank sincerely Dr. Sugio Hayama, Associate Professor of Anatomy, Kansai Medical College, for his valuable advice on feeding and controlling the monkeys.

\section{References}

1) Biel, M \& de Kock, M.A. (1978) Role of alpha-adrenergic receptors in exerciseinduced bronchoconstriction. Respiration, 35, 78-86.

2) Cabezas, G.A., Graf, P.D. \& Nadel. J.A. (1971) Sympathetic versus parasympathetic nervous regulation of airways in dogs. J. appl. Physiol., 31, 651-655.

3) Drazen, J.M. \& Austen, K.F. (1975) Atropine modification of the pulmonary effects of chemical mediators in the guinea pig. J. appl. Physiol., 38, 834-838.

4) Fleish, J.H., Maling, H.M. \& Brodie, B.B. (1970) Evidence for existence of alphaadrenergic receptors in the mammalian trachea. Amer. J. Physiol., 218, 596-599.

5) Grimby, G., Takishima, T., Graham, W., Macklem, P. \& Mead, J. (1968) Frequency dependance of flow resistance in patients with obstructive lung disease. $J$. clin. Invest., 47, 1455-1465.

6) Gross, G.N., Souhrada, J.F. \& Farr, R.S. (1974) The long-term treatment of an asthmatic patient using phentolamine. Chest, 66, 397-401.

7) Henderson, R.W., Shelhamer, H.J., Reingold, B.D., Smith, J.L., Evance, R., III. \& Kaliner, M. (1979) Alpha-adrenergic hyper-responsiveness in asthma - analysis of vascular and pupillary responses. New Engl. J. Med., 300, 642-647.

8) Hirshman, C.A., Downes, H., Farbood, A. \& Bergman, N.A. (1979) Ketamine block of bronchospasm in experimental canine. Brit. J. Anaesth.,51, 713-718.

9) Hyatt, R.E., Zimmerman, I.R., Peter, G.M. \& Sullivan, W.T. (1970) Direct write out of total respiratory resistance. J. appl. Physiol., 28, 675-678.

10) Kaliner, M., Orange, R.P. \& Austen, K.F. (1972) Immunological release of histamine and slow reacting substance of anaphylaxis from human lung. IV. Enhancement by cholinergic and alpha-adrenergic stimulation. J. exp. Med., 136, 556-569.

11) Kerr, J.W., Govindaraj, M. \& Patel, K.R. (1970) Effect of alpha-receptor blocking drugs and disodium cromoglicate on histamine hypersensitivity in bronchial asthma. Brit. med. J., 2, 139-141. 
12) Mathé, A.A., Åström, A. \& Persson, N-Å. (1971) Some bronchoconstricting and bronchodilating responses of the isolated human bronchi: evidence for the existence of alpha-adrenoreceptors. J. Pharm. Pharmocol., 23, 905-910.

13) Miller, M.M., Patterson, R. \& Harris, E.K. (1976) A comparison of immunologic asthma to two types of cholinergic respiratory responses in the rhesus monkey. $J$. Lab. clin. Med., 88, 995-1007.

14) Mue, S., Shibahara, S., Suzuki, S., Takahashi, M., Hida, W., Yamauchi, K., Ohmi, T., Sasaki, T. \& Takishima, T. (1980) Bronchial response to methacholine and histamine in monkeys with beta-adrenergic blockade. J. Allergy clin. Immunol., 65, 338-345.

16) Nadel, J.A. (1976) Airways: Autonomic regulation and airway responsiveness. In: Bronchial Asthma, edited by E.B. Weiss \& M.S. Segal, Little Brown and Company, Boston, pp. 156-162.

17) Patterson, R. \& Harris, E.K. (1976) The effect of cholinergic and anticholinergic agents on the primate model of allergic asthma. J. Lab. clin. Med., 87, 65-72.

18) Patterson, R. \& Kelly, F.J. (1974) Animal models of the asthmatic state. Ann. Rev. Med., 25, 53-68.

19) Patterson, R., Talbot, H.C. \& Roberts, M. (1971) Reverse passive respiratory reactions due to anti-IgE in rhesus monkeys. Clin. exp. Immunol., 9, 267-274.

20) Simonsson, B.G., Jacob, F.M. \& Nadel, J.A. (1967) Role of autonomic nervous system and the cough reflex in the increased responsiveness of airways in patients with obstructive airway disease. J. clin. Invest., 46, 1812-1818.

21) Simonsson, B.G., Svedmyr, N. \& Skoogh, B.E. (1972) In vivo and in vitro studies on alpha-receptors in human airways: potentiation with bacterial endotoxin. Scand. J. resp. Dis., 53, 227-236.

22) Spector, S.L. \& Farr, R.S. (1975) A comparison of methacholine and histamine inhalations in asthmaticus. J. Allergy clin. Immunol., 56, 308-317.

23) Straus, H.W. (1937) Studies in experimental hypersensitiveness in the rhesus monkey. II. Passive local cutaneous sensitization with human reaginic sera. J. Immunol., 32, 251-267.

24) Szentivanyi, A. (1968) The beta-adrenergic theory of the atopic abnormality in bronchial asthma. J. Allergy, 42, 203-232.

25) Weiner, N. (1980a) Atropine, scopolamine and related antimuscarinic drugs. In: The Pharmacological Basis of Therapeutics. 6th Ed., edited by A.G. Gilman, L.S. Goodman \& A. Gilman, MacMillan, New York, pp. 120-137.

26) Weiner, N. (1980b) Isoproterenol, pharmacological actions. In: The Pharmacological Basis of Therapeutics. 6th Ed., edited by A.G. Gilman, L.S. Goodman \& A. Gilman, MacMillan, New York, pp. 153-154.

27) Weiner N. (1980c) Tolazoline and phentolamine. In: The Pharmacological Basis of Therapeutics. 6th Ed., edited by A.G. Gilman, L.S. Goodman \& A. Gilman, MacMillan, New York, pp. 183-189.

28) Yu, D.Y.G., Galant, S.P. \& Gold, W.M. (1972) Inhibition of antigen-induced bronchoconstriction by atropine in asthmatic patients. J. appl. Physiol., 32, 823-828. 